\title{
IDENTIFICATION OF DROUGHT TOLERANT MUTANT LINES OF TEF [ERAGROSTIS TEF (ZUCC.) TROTTER]
}

\author{
Regula Blösch, Abiel Rindisbacher, Sonia Plaza-Wüthrich, \\ Nora Röckel, Annett Weichert, Gina Cannarozzi \\ and Zerihun Tadele \\ University of Bern, Institute of Plant Sciences, Switzerland
}

Introduction: Tef [Eragrostis tef (Zucc.) Trotter] is the major food crop in Ethiopia where it is annually cultivated on about $30 \%$ of the total area allocated to cereals. The productivity of tef is, however, significantly reduced by drought which can occur at either the early or the late developmental stage of the crop.

Methodology: A total of 10,000 EMS (ethyl methane sulfonate) mutagenized $M_{2}$ tef populations were screened first for early and second for terminal drought tolerance. The performance of candidate lines was investigated using diverse agronomical and physiological parameters.

Results and discussion: Several promising lines were obtained for both early and terminal drought tolerance. Among these, genotypes with outstanding performance were found for two drought tolerant tef lines targeting early drought tolerance ( $d t t 2$ and $d t t 13$ ) and three terminal drought tolerant lines targeting terminal drought tolerance ( $t d t 9, t d t 15$ and $t d t 19)$.

Conclusions: Candidate lines for both early and terminal drought tolerance will play vital roles in developing drought tolerance in tef improvement.

KEY WORDS: DROUGHT TOLERANCE, ERAGROSTIS TEF, ORPHAN CROP, MOISTURE SCARCITY, TEF

\section{Introduction}

Food security can be improved not only by focusing on globally important major crops but also on locally important crops commonly known as orphan crops (Tadele \& Assefa, 20I2). Although orphan or indigenous crops often perform better than major world crops under extreme environmental conditions and fit to the socio-economic conditions of the areas in which they are grown, they are also subject to a number of environmental and policy-related constraints (Tadele, 20I6, 20I7, 20I8).

The Tef Improvement Project which is based at the University of Bern implements diverse genetic and genomic tools to develop tef lines with increased productivity (Cannarozzi, Chanyalew, et al., 20I8; Cannarozzi et al., 20I4; Cannarozzi, Weichert, et al., 2018; Jost et al., 2015). Tef [Eragrostis tef (Zucc.) Trotter] is the most important cereal crop in the Horn of Africa, especially in Ethiopia, where it is annually cultivated on about three million hectares of land accounting for $30 \%$ of the total area under cereal crops (CSA, 2015) Fi- 
gure $\mathbf{I}$. While the national area under tef cultivation increased by $38.1 \%$ from $2 . \mathrm{I}$ million ha in 1995 to 2.9 million ha in 2015 , the total production has raised by $150 \%$ during the same period (from I.8 million tons in 1995 to 4.5 million tons in 2015). This boost in production was mainly due to substantial increases in the dissemination of high yielding varieties (Assefa et al., 20II).

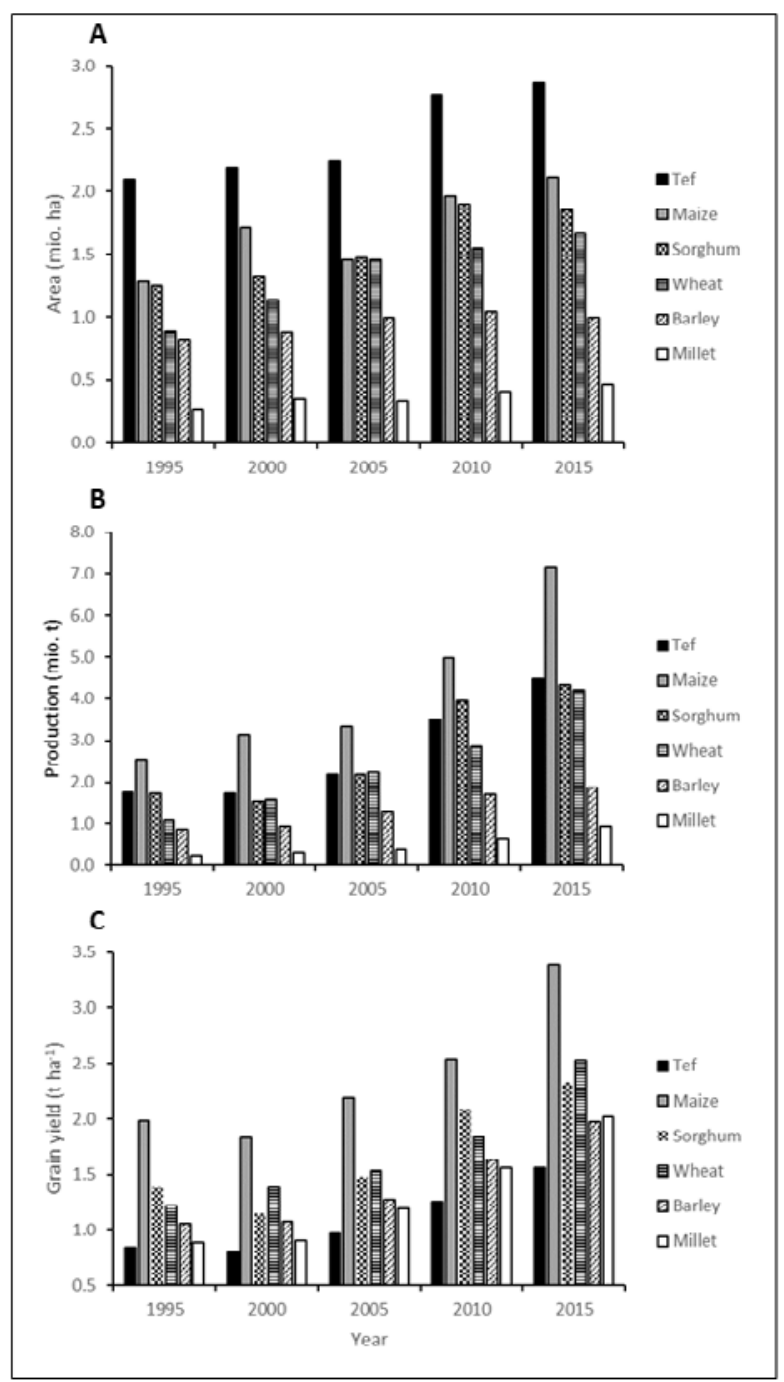

Figure 1: Tef plays significant role in the Ethiopian economy. (A) the total area cultivated, (B) the total production, and (C) grain yield for tef and other cereal crops in Ethiopia from 1995 to 2015. Adapted from (CSA, 2015) 
In addition to its ability to grow under diverse environmental conditions, tef grain is nutritious due to its high protein and mineral content (Abebe et al., 2007; Bultosa, Hall, \& Taylor, 2002) and healthy because of the absence of gluten (Spaenij-Dekking, Kooy-Winkelaar, \& Koning, 2005), which makes it an alternative food for people suffering from celiac disease. Despite its adaptation to extreme environmental conditions, the productivity of tef is low in Ethiopia. The major yield-limiting factors to tef production are the lack of cultivars tolerant to lodging and to prolonged drought (Assefa et al., 20II). Lodging (permanent displacement of the stem from the upright position) is the major production constraint in tef. Tef possesses tall weak stems that easily succumb to lodging caused by wind or rain causing severe reductions in both the yield and the quality of the grain and the straw. To circumvent this problem, we developed semi-dwarf and lodging-tolerant tef lines (Jost, et al., 2015) which have been incorporated into the national tef breeding program in Ethiopia. This has allowed us to release a new variety called Tesfa (Cannarozzi, Chanyalew, et al., 2018) that is being disseminated to small-holder farmers in the country.

Here, we report on the development of drought tolerant tef lines. Both early drought which occurs during seedling establishment, and terminal drought which occurs during the flowering and grain filling period were targeted. Compared to most cereal crops cultivated in Ethiopia, tef is more tolerant to drought. However, due to recent increases in both the intensity and the area affected by drought, the productivity of tef has been severely affected (Assefa et al., 20II). An earlier study on three Eragrostis species showed that E. capensis was drought-intolerant while tef is more tolerant than E. capensis but much less tolerant than E. curvula (Balsamo, Willigen, Bauer, \& Farrant, 2006) indicating that tef is not the most tolerant species in the genus Eragrostis. Water deficit studies on the tef variety Tsedey during establishment, vegetative, flag leaf and grain filling developmental stages showed that the grain filling stage of tef was the most sensitive to water stress and severe water stress caused significant reduction in the physiological performance of tef (Mengistu, 2009).

A more recent study has also shown that there is cross-talk between abiotic stress tolerance and gibberellic acid response where the application of the GA inhibitor paculobutrazol (PBZ) to cereal crops significantly reduced the plant height and increased lodging tolerance. Remarkably, PBZ also enhanced the tolerance of both tef and finger millet to moisture deficit including moisture scarcity. Tef plants treated with PBZ did not exhibit drought-related symptoms and their stomatal conductance was unaltered, leading to higher shoot biomass and grain yield. Semi-dwarf rice mutants altered in GA biosynthesis, were also shown to have improved tolerance to dehydration (Plaza-Wüthrich, Blösch, Rindisbacher, Cannarozzi, \& Tadele, 20I6).

Response to drought has been studied on improved varieties and landraces (Assefa et al., 20I5; Plaza-Wüthrich, et al., 20I6; Plaza-Wüthrich, Cannarozzi, \& Tadele, 20I3). However, no experiment has yet been conducted using drought tolerant candidate lines derived from induced mutagenized tef populations. The goal of the current study was, therefore, to first screen for candidate lines with enhanced drought tolerance, followed by a detailed investigation into the performance of the candidate lines. 


\section{Methodology}

Plant materials and growth conditions

Two ethyl methanesulfonate (EMS) mutagenized $\mathrm{M}_{2}$ populations derived from Tsedey and Dukem tef varieties were used. Tsedey is an early maturing variety and adapts to semi-arid areas, whereas Dukem is a late maturing variety that performs best in high rainfall areas (Assefa, et al., 2015). |While $5000 \mathrm{M}_{2}$ populations derived from Tsedey variety were used for screening for early drought tolerance, $3000 \mathrm{M}_{2}$ populations derived from Tsedey and $2000 M_{2}$ populations derived from Dukem variety were used for screening for terminal drought tolerance.

Plants were grown for three weeks under long-day ( $\mathrm{I} 6 \mathrm{~h}$ light at $24^{\circ} \mathrm{C}$ and $8 \mathrm{~h}$ dark at $\mathrm{I} 8$ ${ }^{\circ} \mathrm{C}$ ) followed by short-day ( $8 \mathrm{~h}$ light at $22{ }^{\circ} \mathrm{C}$ and $\mathrm{I} 6 \mathrm{~h}$ dark at $20^{\circ} \mathrm{C}$ ). The photosynthetic photon flux (PPF) measured by a quantum meter (Apogee Instruments, Logan, UT) were I62-I75 $\mu \mathrm{mol} \mathrm{m}^{-2} \mathrm{~s}^{-1}$ under long-day and $\mathrm{I} 23-\mathrm{I} 32 \mu \mathrm{mol} \mathrm{m}^{-2} \mathrm{~s}^{-1}$ and under short-day conditions.

The soil used for experiments consisted of five parts of topsoil, four parts of turf and two parts of quartz sand. Plants were fertilized once a week with Hauert Plantaktiv $16+6+26$ type $\mathrm{K}$ containing $\mathrm{r} 6 \% \mathrm{~N}, 6 \% \mathrm{P}, 26 \% \mathrm{~K}, 2 \% \mathrm{Mg}$ and micronutrients [0.02\% B, $0.04 \% \mathrm{Cu}$ (EDTA), о.I\% Fe (EDTA), о.05\% Mn (EDTA), о.ог\% Mo, о.о \% Zn (EDTA)].

\section{Screening for early drought tolerance}

The primary screening was carried out using I0-20 seeds of the 5000 EMS mutagenized $\mathrm{M}_{2}$ populations on soil on trays which were watered to field capacity during seed sowing. After germination, drought condition was initiated by withholding water. Primary screening was made when the original Tsedey plants showed severe drought stress phenotypes such as dry, dark-green, pin-shaped and rolled-up leaves which lead to dead plants. Candidate lines from the primary screening were transplanted to new pots and re-watered to grow to maturity. Secondary screening was made on candidate lines obtained from the primary screening to validate the results.

\section{Screening for terminal drought tolerance}

Screening was made using I0-20 seeds of the 5000 EMS mutagenized $\mathrm{M}_{2}$ populations derived from Tsedey (3000 populations) and Dukem (2000 populations). Seeds were sown on soil and watered until the flowering period at which drought was induced to simulate the dry-spell in the semi-arid tef growing regions in Ethiopia, which normally coincides with the flowering and grain filling period of tef. Before initiating the drought treatment, all trays were first saturated with water to field capacity in order to ensure equal starting conditions. Subsequently no water was added until the end of the drought treatment when obvious sensitivity and weak phenotypes were observed for original tef lines used for mutagenesis. The drought treatment was followed by re-watering of all plants until maturity in order to determine the effect on yield and yield-related traits. 


\section{Data collection}

Agronomic traits such as days to flowering and maturity, grain filling period (time from flowering to physiological maturity), plant height, leaf length, number of tillers per plant, panicle length, seed yield, Ioo-seed weight, harvest index and shoot dry biomass were measured. In addition, leaf rolling and stomatal conductance was measured during drought treatment. Chlorophyll content was measured using a Minolta Chlorophyll Meter, SPAD-502 (Minolta Camera CO., LTD. Japan). The chlorophyll meter measures a SPAD-value (arbitrary unit), which corresponds to the relative chlorophyll content in the leaf. Three replicate measurements per leaf were taken to calculate the mean value per leaf and the measurement was always done in the middle of the sixth fully developed leaf. The water content of shoots and roots was quantified as follows: water content $=(\mathrm{fw}-\mathrm{dw})$ $\mathrm{ldw}$, where fw is fresh weight and $\mathrm{dw}$ is dry weight. Stomatal conductance $\left(\mathrm{mmol} \mathrm{m}^{-2} \mathrm{~s}^{-1}\right)$ was measured using a Delta-T Porometer (Decagon Devices, Inc., Steady State Diffusion Porometer, Model SC-I). Measurements were taken both from adaxial and abaxial side of the middle of the seventh fully expanded leaf. The total stomatal conductance was calculated by summing up the adaxial and abaxial stomatal conductance of a leaf. The values for stomatal conductance of totally desiccated leaves due to osmotic stress were no more measurable and assumed to be zero.

\section{Data analysis}

Statistical analyses were performed using the software SPSS I3.0 (IBM, Chicago, IL). Non-parametric tests were chosen in order to compare differences between the treatments $(\mathrm{p} \leq \mathrm{0.05})$. For $\mathrm{K}$ independent samples, Kruskal-Wallis tests were used, whereas for two independent samples, Mann-Whitney U tests were conducted.

\section{Results and Discussion}

\section{Early drought tolerance}

The primary screening of 5000 mutagenized tef populations for early drought tolerance resulted in 24 candidate tef lines which resist moisture scarcity that occurs during seedling establishment. After three weeks of withholding the application of water, the original Tsedey tef line was severely affected by the moisture deficit where these led the plants to became dry, dark-green, and with pin-shaped and rolled-up leaves. On the other hand, the candidate tef lines exhibited little effect as the leaves remain green and unfolded. These candidate lines were given the name drought tolerant tef ( $\mathrm{dtt}$ ). The 24 candidate lines recovered from primary screening were provided with additional moisture in order to obtain seeds for the next generation tests. At the secondary screening where 24 candidates from the primary screening were used for investigation, two promising lines called $d t t 2$ and $d t t 13$ were selected. Further morphological and physiological studies were made on these two drought tolerant lines.

Selected agronomical properties of the two candidates and the original Tsedey variety are shown in Table I. For most of these parameters, the differences among the three tef genotypes were not significant $\mathrm{p}<0.05$. The traits not significantly altered by drought include: plant height, numbers of tillers, and number of panicles per plant. This indicates that 
the two candidate lines were not negatively altered in terms of these vital traits. Hence, further breeding to enhance the performance of these traits in $\mathrm{dtt}$ lines might not be necessary. Although flowering time was similar in the three genotypes, the maturity period was significantly $(\mathrm{p}<0.05)$ shorter in the two candidate lines compared to the Tsedey line. This hastened maturity in the two candidate lines might be a mechanism or strategy to escape drought.

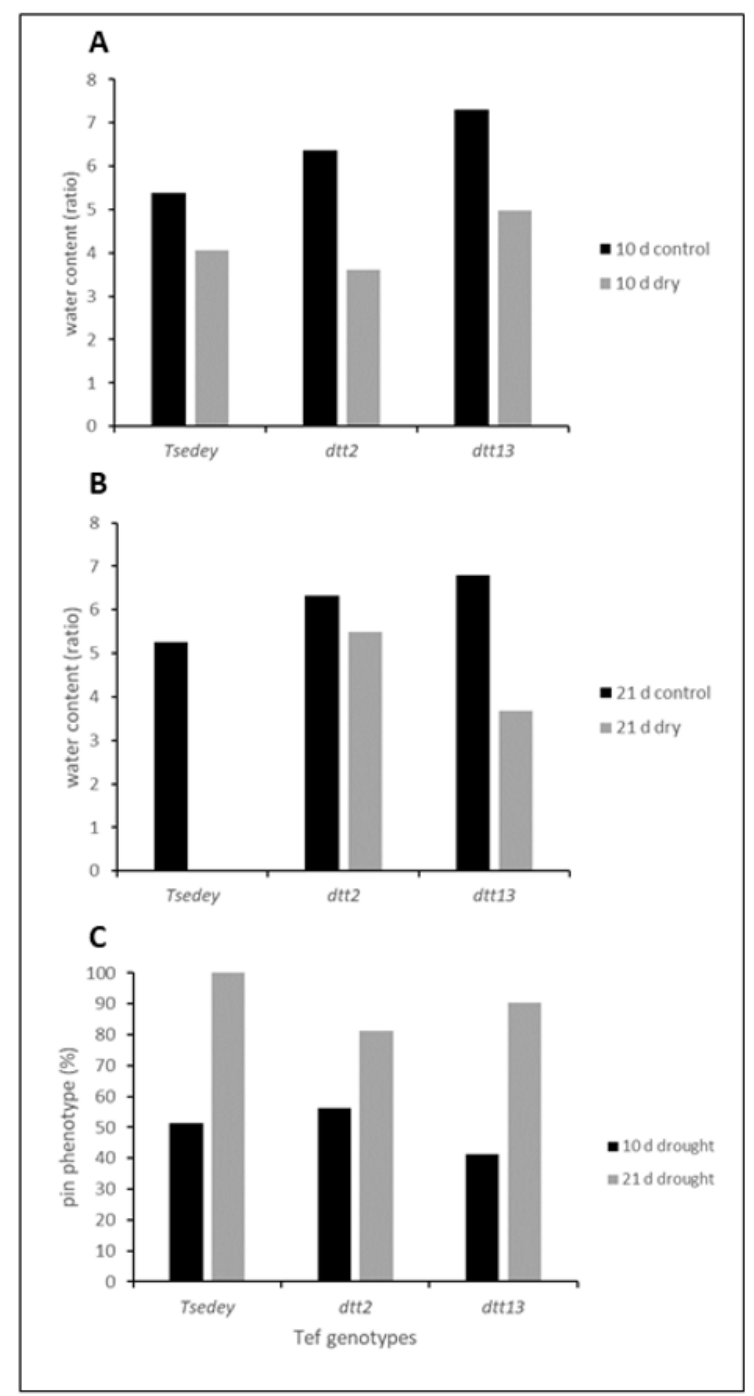

Figure 2: Water content and stress symptoms of control and plants from which water was withheld for 10 and 21 days. (A) water content at $10 \mathrm{~d}$; (B) water content at $21 \mathrm{~d}$; and (C) percent of plants with stressed or pin phenotype at 10 and 21 days. 


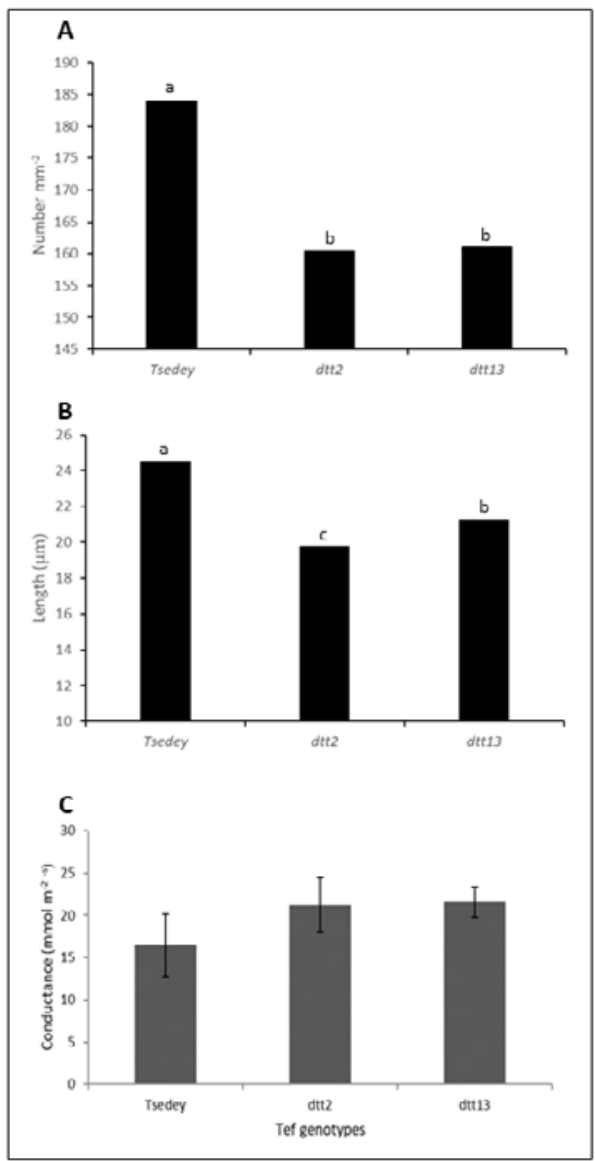

Figure 3: Stomata-related characterstics for two drought tolerant tef ( $d t t)$ lines and the original Tsedey cultivar three weeks after germination. (A) stomata length on adaxial side; (B) stomata number on adaxial side; and (C) stomatal conductance.

The water content of the control and treated plants was quantified after Io and 2I days of no watering. At Io days of no water application, the water content of the plant was similar among the three genotypes (Fig. 2A) indicating the tolerance of Tsedey to a modest level of moisture scarcity. Although the moisture content was similar for the three genotypes after ro days of drying, under normal watering conditions the two $\mathrm{dtt}$ lines had elevated levels of moisture content compared to Tsedey. After 2I days of drought, water content could not be quantified for Tsedey as the plant died due to the severity of moisture deficit. However, the moisture content in the two $d t t$ lines was not altered (Fig. 2B). The intensity of stress due to drought can also be assessed by the pin-shape phenotype which appears on severely affected plants where the leaves roll to form a pin-like phenotype. Due to this, the pin-phenotype is used in cereal crops as an indicator to susceptibility to drought. 


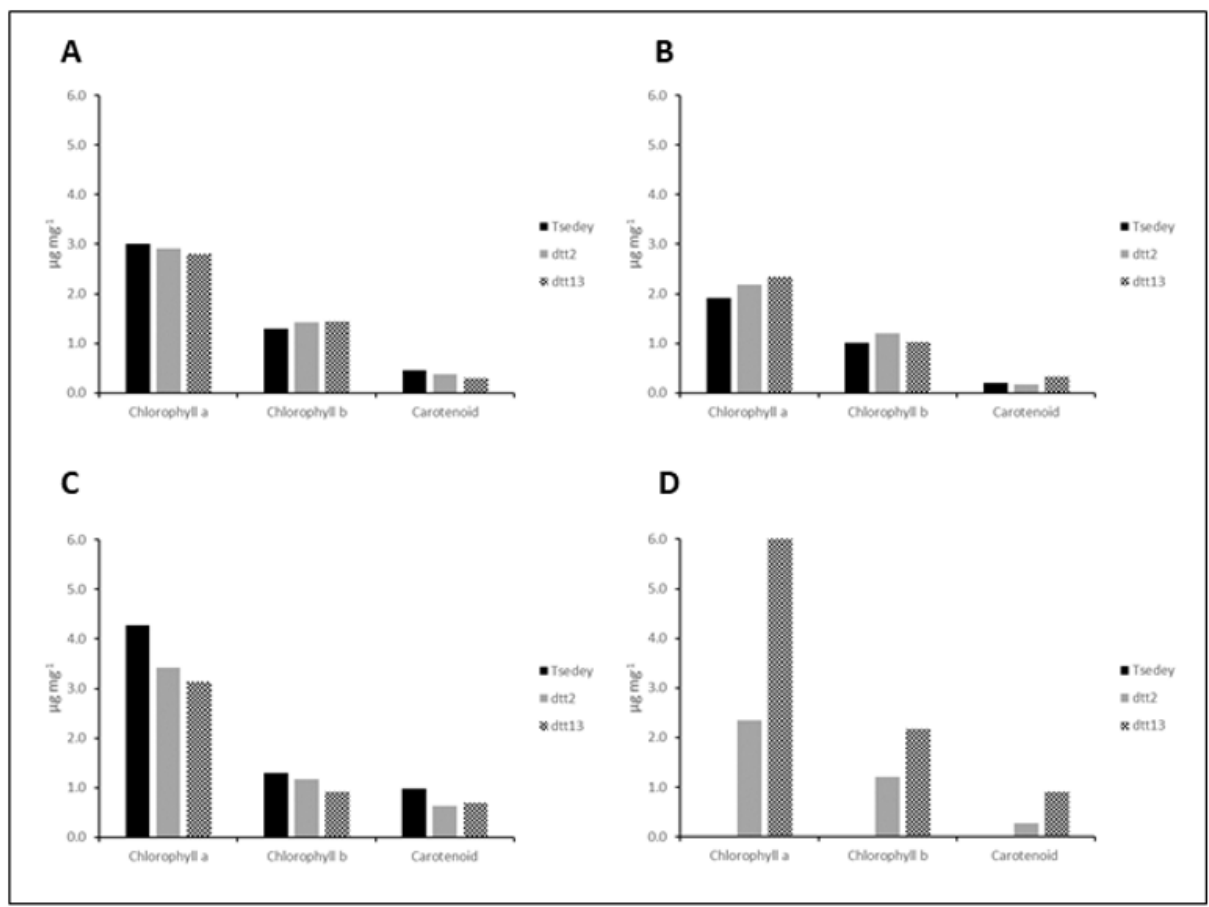

Figure 4: Chorophyll and carotenoid content of $d t t$ and Tsedey lines when exposed to 10 and 21 days of drought. (A) and (B) well-watered; (C) and (D) drought conditions; (A) and (C) for 10 days; (B) and (D) for 21 days.

The pin-phenotype after to days of drought was comparable among the three genotypes (Fig. ${ }_{2}$ ) indicating that this level of drought on tef is mild as it has little negative effect on moisture level and architecture of the plant. At 2I days of drought, however, all Tsedey leaves exhibited the pin-phenotype while a maximum of $80-90 \%$ of $d t t$ lines had the pin-phenotype.

Stomata-related parameters were also investigated in three-week old Tsedey and the two $\mathrm{dtt}$ lines. Both the number and size of stomata were significantly reduced at the adaxial or upper-side of the leaf in the dtt lines compared to the Tsedey line (Fig. 3A \& B). This might prevent the dtt lines from losing high amount of water due to substantial reduction in stomata length and number. On the other hand, stomatal conductance was similar in the two dtt and Tsedey lines (Fig. ${ }_{3} \mathrm{C}$ ).

Chlorophyll and carotenoid contents were investigated in plants subjected to Io and 2I days drought. After Io days of drought, only mild changes were observed among the three genotypes for chlorophyll a, chlorophyll b and carotenoid (Fig. 4). However, after 2I days of drought, no pigment was measured for Tsedey due to the death of the plant. However, the levels of the pigments were unaltered in $d t t 2$ line. Surprisingly, the contents 
of these pigments especially those of chlorophyll a and b were elevated several folds in the $d t t 13$ line.

\section{Terminal drought tolerance (tdt)}

The screening of $3000 \mathrm{M}_{2}$ mutagenized populations derived from the Tsedey variety resulted in 15 candidate lines which were later reduced to three. Whereas, the screening of $2000 M_{2}$ mutagenized populations derived from the Dukem variety resulted in 20 candidates which were later reduced to three promising lines. Detailed investigations were made in the latter three lines which were selected as the best candidates against terminal drought that occurs during the flowering and grain filling period of tef plant. These were tdt 4-9, tdt 4-15 and tdt 4-19. Visually, the three candidate lines were similar to each other and indistinguishable from Dukem (Fig. 5 A-D). However, at later stage of development, substantial differences appeared especially between the three candidates and the Dukem variety.

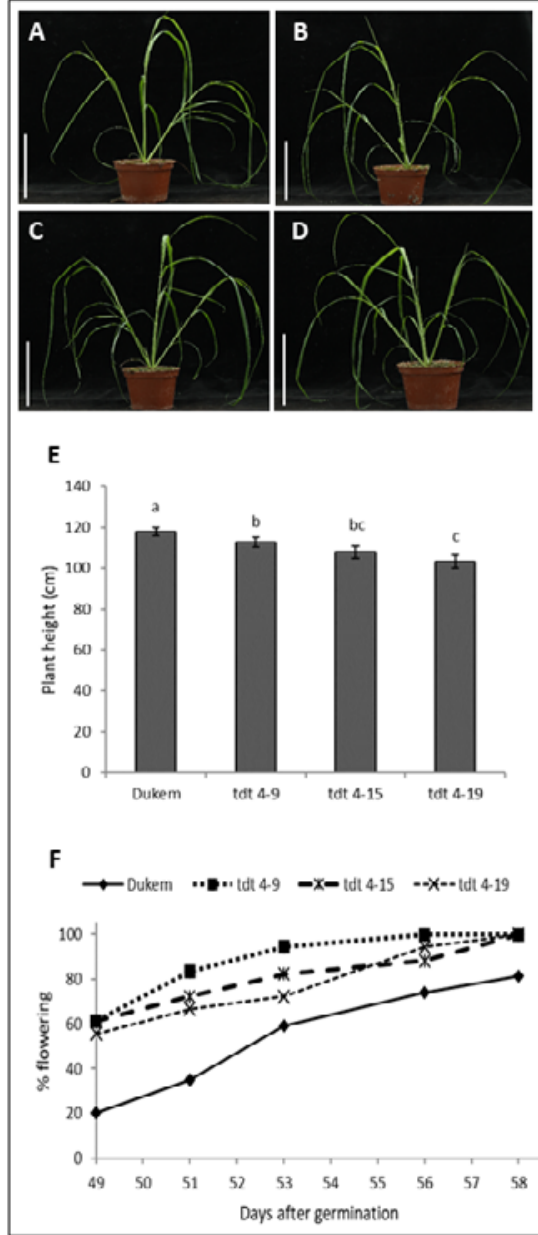

Figuer 5. Morphological and phenotypic properties of of terminaly drought tolerent ( $t d t$ t tef lines and original Dukem cultivar. Pictures of (A) Dukem; (B) tdt 4-9; (C) tdt 4-15; and (D) tdt 4-19. (E) plant height and $(F) \%$ flowering of the four genotypes. 
The plant height was measured at several time points during the development. All candidates were significantly ( $\mathrm{p} \leq 0.05$ ) smaller prior to the drought treatment at 49 days after germination, compared to the original Dukem line (data not shown). Among the three candidate lines, tdt 4-9 was the tallest while tdt 4-19 was the shortest (Fig. 5E). The difference between these two lines was significant at $\mathrm{p} \leq 0.05$ but the differences between each of these two lines and $t d t 4-15$ were not significant. The number of tillers and number of panicles per plant were not significantly altered between three tdt lines and Dukem. The flowering, defined as initiation of first inflorescence, was tracked starting 49 days after germination, when the flowering ratio of the plants was estimated $50 \%$ by visual investigation and continued until the candidate lines reached a flowering ratio of $100 \%$.

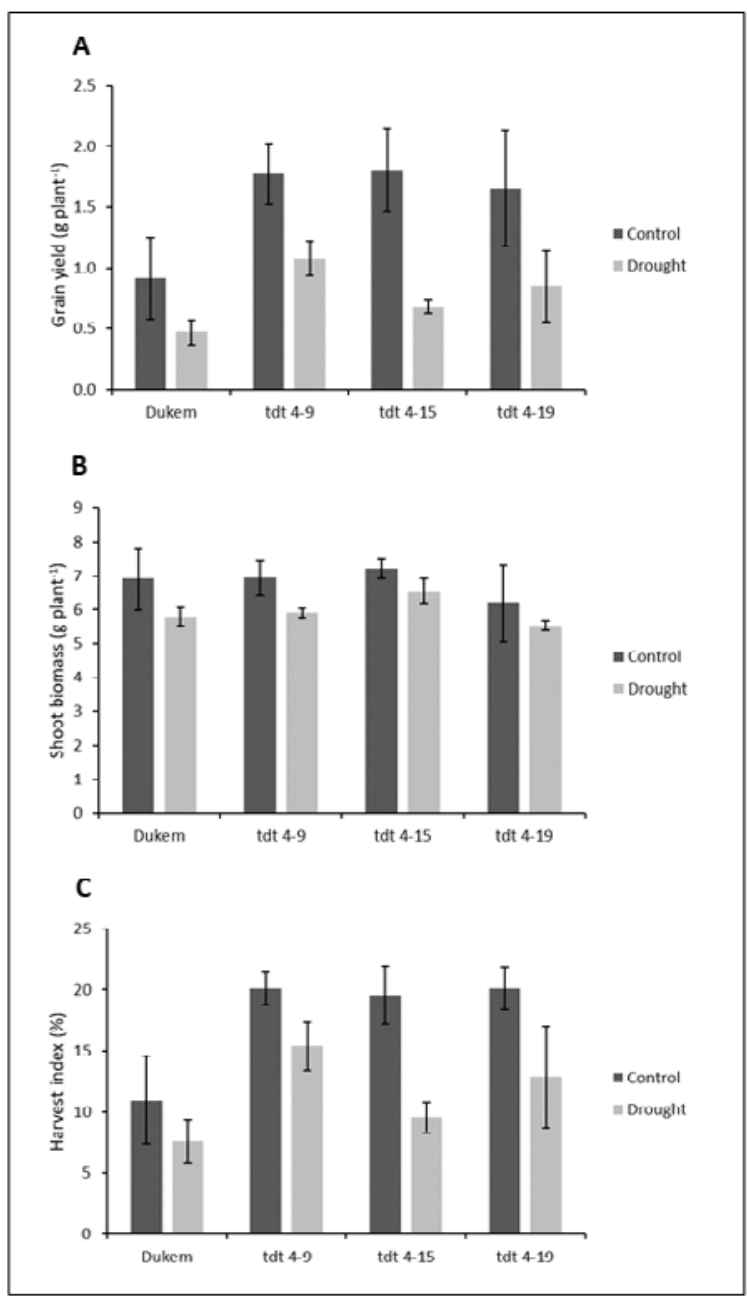

Figure 6: Effect of drought on agronomic properties of two $t d t$ lines and the Dukem cultivar. (A) shoot biomass; (B) grain yield; (C) harvest index. 
At 49 days after germination, only $20 \%$ of Dukem set flowers while about $60 \%$ of the three tdt lines reached flowering during the same period (Fig. 5 F). It took only ro additional days for the two tdt lines to achieve Ioo\% flowering while Dukem had a maximum of $80 \%$ flowering by this time. This early flowering which is also an early maturity in the tdt lines, enabled these three candidate lines to escape from drought that occurs during the late developmental stage, which coincides with the flowering and grain filling periods.

Grain yield and shoot biomass were measured after the harvest and the harvest index was calculated as the ratio between grain yield and shoot dry biomass. All three drought tolerant candidate lines gave higher grain yield over Dukem under both well-watered and drought conditions (Fig. 6). The yield advantages of the candidates over Dukem ranged from $80-89 \%$ under well-watered and 2I to I29\% under drought conditions. However, the shoot biomass of the three candidates and Dukem were similar under both moisture regimes. Since the drought treatment was applied during flowering time, plants developed the bulk of their biomass during this time. The harvest index is a key parameter extensively applied by breeders and agronomists as it measures the proportion of grain to the total biomass. In this study, the values of harvest index were significantly ( $\mathrm{p} \leq \mathrm{O} . \mathrm{I}$ ) higher in the three $t d t$ lines compared to the Dukem variety especially under well-watered condition where they were over $80 \%$ superior in $t d t$ lines. This indicates that $t d t$ lines are the preferred genotypes to Dukem in both good years when there is enough precipitation, as well as bad years when moisture levels are extremely low.

Drought tolerance in tef can also be developed from over 5000 tef landraces collected from diverse tef growing regions in Ethiopia with extreme divergence in terms of climate and soil. Several studies from recent years found tef accessions with increased tolerance to drought (Abraha et al. 2016; Abraha et al. 2017).

In addition, our recent study identified $\mathrm{I} 47$ novel and unique putative miRNA precursors from tef which are associated to drought (Martinelli et al., 20I8). Prediction of the targets of these miRNAs resulted in the identification of many transcription factors that may be potential targets for improvement of drought resistance.

\section{Conclusion}

Screening mutagenized tef populations enabled us to obtain several candidate tef lines with enhanced drought tolerance. Based on their outstanding performance, $d t t 2$ and $d t t$ 13 were selected for early drought tolerance while $t d t$ 4-9, tdt 4-15 and tdt 4-19 were chosen for terminal drought tolerance. The unique morphological difference between these $\mathrm{dtt}$ lines and the original Tsedey line is stomata. The stomata at the adaxial or upper side of the two $\mathrm{dtt}$ lines were smaller in size and fewer in number compared to Tsedey. These small-sized stomata in $\mathrm{dtt}$ lines might contribute towards making the plant more tolerant to drought as less water is lost through transpiration. A possible explanation for the terminal drought tolerance in the $t d t$ lines could be their early flowering and maturity as well as higher tillering number that leads to an increased grain yield even under well-watered condition compared to the Dukem. Candidates from both early and terminal drought tolerance were introgressed to high-yielding and improved tef varieties in Ethiopia and are currently being investigated at multiple sites in drought prone areas. 


\section{References}

Abebe, Y., Bogale, A., Hambidge, K. M., Stoecker, B. J., Bailey, K., \& Gibson, R. S. (2007). Phytate, zinc, iron and calcium content of selected raw and prepared foods consumed in rural Sidama, Southern Ethiopia, and implications for bioavailability. Journal of Food Composition and Analysis, 20(3-4), I6II68. doi: DOI I0.Ior6/j.jfca.2006.09.003

Abraha, M.T, Shimelis, H., Laing, M., Assefa, K. (2016). Performance of tef [Eragrostis tef (Zucc.) Trotter] genotypes for yield and yield components under drought-stressed and non-stressed conditions. Crop Science 56, 1799-1806

Abraha, M.T, Shimelis, H, Laing, M., Assefa, K. (2017). Selection of drought-tolerant tef (Eragrostis tef) genotypes using drought tolerance indices. South African Journal of Plant and Soil 34, 29I-300

Assefa, K., Cannarozzi, G., Girma, D., Kamies, R., Chanyalew, S., Plaza-Wuthrich, S., ... Tadele, Z. (2015). Genetic diversity in tef [Eragrostis tef (Zucc.) Trotter]. Frontiers in plant science, 6. doi: Doi 10.3389/Fpls.2015.00177

Assefa, K., Yu, J. K., Zeid, M., Belay, G., Tefera, H., \& Sorrells, M. E. (20II). Breeding tef [Eragrostis tef (Zucc.) trotter]: conventional and molecular approaches. Plant Breeding, 130(I), I-9. doi: DOI I0.IIII/j.I439-0523.2010.01782.X

Balsamo, R. A., Willigen, C. V., Bauer, A. M., \& Farrant, J. (2006). Drought tolerance of selected Eragrostis species correlates with leaf tensile properties. Annals of Botany, 97, 985-991. doi: Doi I0.1093/Aob/Mcio68

Bultosa, G., Hall, A. N., \& Taylor, J. R. N. (2002). Physico-chemical characterization of grain tef [Eragrostis tef (Zucc.) Trotter] starch. Starch-Starke, 54(Io), 46I-468.

Cannarozzi, G., Chanyalew, S., Assefa, K., Bekele, A., Blosch, R., Weichert, A., ... Tadele, Z. (2018). Technology generation to dissemination: lessons learned from the tef improvement project. Euphytica, 214(2), 31. doi: 10.1007/sio68I-0I8-2115-5

Cannarozzi, G., Plaza-Wuthrich, S., Esfeld, K., Larti, S., Wilson, Y. S., Girma, D., ... Tadele, Z. (2014). Genome and transcriptome sequencing identifies breeding targets in the orphan crop tef (Eragrostis tef). [Research Support, Non-U.S. Gov't]. BMC genomics, 15, 58I. doi: 10.II86/I47I2I64-I5-58I

Cannarozzi, G., Weichert, A., Schnell, M., Ruiz, C., Bossard, S., Blösch, R., ... Tadele, Z. (2018). Waterlogging affects plant morphology and the expression of key genes in tef (Eragrostis tef). Plant Direct, 2018, I-22.

CSA. (2015). Agricultural sample survey 2014/2015. Volume I. Report on area and production of major crops. Statistical Bulletin 578. Addis Ababa, Ethiopia: Central Statistical Agency (CSA).

Jost, M., Esfeld, K., Burian, A., Cannarozzi, G., Chanyalew, S., Kuhlemeier, C., ... Tadele, Z. (2015). Semi-dwarfism and lodging tolerance in tef (Eragrostis tef) is linked to a mutation in the alphaTubulin I gene. Journal of Experimental Botany, 66, 933-944. doi: Io.1093/jxb/eru452

Martinelli, F., Cannarozzi, G., Balan, B., Siegrist, F., Weichert, A., Blosch, R., \& Tadele, Z. (2018). Identification of miRNAs linked with the drought response of tef [Eragrostis tef (Zucc.) Trotter]. J Plant Physiol, 224-225, 163-172. doi: ro.ror6/j.jplph.2018.02.01I

Mengistu, D. K. (2009). The influence of soil water deficit imposed during various developmental phases on physiological processes of tef (Eragrostis tef). Agriculture Ecosystems \& Environment, 132(3-4), 283-289. doi: DOI ro.1016/j.agee.2009.04.013

Plaza-Wüthrich, S., Blösch, R., Rindisbacher, A., Cannarozzi, G., \& Tadele, Z. (20r6). Gibberellin deficiency confers both lodging and drought tolerance in small cereals. Front. Plant Sci., 7, 643.

Plaza-Wüthrich, S., Cannarozzi, G., \& Tadele, Z. (2013). Genetic and phenotypic diversity in selected genotypes of tef [Eragrostis tef (Zucc.)] Trotter. African Journal of Agricultural Research 8, 104I-I049.

Spaenij-Dekking, L., Kooy-Winkelaar, Y., \& Koning, F. (2005). The Ethiopian cereal tef in celiac disease. [Letter]. The New England journal of medicine, 353, I748-1749. doi: I0.I056/NEJMc05I492

Tadele, Z. (2016). Drought adaptation in millets. In A. Shanker \& C. Shanker (Eds.), Abiotic and Biotic Stress in Plants: Recent Advances and Future Perspectives (pp. 639-662): InTech. 
Tadele, Z. (2017). Raising crop productivity in Africa through intensification. Agronomy J., 7, 22.

Tadele, Z. (2018). African orphan crops under abiotic stresses: challenges and opportunities. Scientifica, 2018, I451894.

Tadele, Z., \& Assefa, K. (2012). Increasing food production in Africa by boosting the productivity of understudied crops. Agronomy, 2(4), 240-283.

\begin{tabular}{l|c|c|c}
\hline \multirow{2}{*}{ Parameters } & \multicolumn{3}{c}{ Genotypes } \\
\cline { 2 - 4 } & Tsedey & $\boldsymbol{d t t}-\mathbf{2}$ & $\boldsymbol{d t t - 1 3}$ \\
\hline Plant height (cm) & $85.0 \mathrm{ab}$ & $87.6 \mathrm{a}$ & $77.2 \mathrm{~b}$ \\
\hline Tillers per plant (number) & $3.9 \mathrm{a}$ & $5.6 \mathrm{a}$ & $4.0 \mathrm{a}$ \\
\hline Panicles per plant (number) & $5.8 \mathrm{a}$ & $7.0 \mathrm{a}$ & $7.0 \mathrm{a}$ \\
\hline Days to flowering & $103.3 \mathrm{a}$ & $99.3 \mathrm{a}$ & $103.7 \mathrm{a}$ \\
\hline Days to maturity & $146.6 \mathrm{a}$ & $136.3 \mathrm{~b}$ & $137.0 \mathrm{~b}$ \\
\hline Grain filling period (days) & $38.8 \mathrm{a}$ & $37.0 \mathrm{a}$ & $35.7 \mathrm{a}$ \\
\hline Harvest index (ratio) & $0.16 \mathrm{a}$ & $0.21 \mathrm{a}$ & $0.19 \mathrm{a}$ \\
\hline
\end{tabular}

Table 1: Agronomic properties of the two drought tolerant candidate tef lines (dtt2 and dtt13) along with the original Tsedey cultivar. Means in a row followed with the same letter are not significantly different at $p<0.05$. 
